\title{
Modern Technologies for Rendering Information Support to Cogeneration Steam Turbine Units in Their Design and Operation Stages
}

\author{
V. I. Brezgin ${ }^{a}$, Yu. M. Brodov ${ }^{a}$, A. A. Chubarov ${ }^{b}$, and D. V. Brezgin ${ }^{a}$ \\ ${ }^{a}$ Ural Federal University, ul. Mira, 19, Yekaterinburg, 620002 Russia \\ ${ }^{b}$ Ural Turbine Works, ul. Frontovykh Brigad 18, Yekaterinburg, 620017 Russia
}

\begin{abstract}
Application of modern information technologies in different stages of the lifecycle of cogeneration turbines is considered as one of possible ways for improving their competitiveness. Specific features relating to rendering information support for steam turbine units during the periods of their design and operation, which are the main stages of their life cycle, are presented. Three-dimension modeling, adaptive, and parametric design technologies are applied in the equipment design stages. Information support technologies developed by the authors are applied during the operation stage. Information is integrated by using a product lifecycle management (PLM) system.
\end{abstract}

Keywords: turbine, steam-turbine unit, designing, operation, information support, modeling, lifecycle

DOI: $10.1134 / \mathrm{S} 004060151308003 \mathrm{X}$

Increased differentiation of the social and economic situation in regions has become one of the consequences resulting from the changes that occurred in Russia in the 1990s. In this connection, we are witnessing increased migration mobility of population. A growth of population and, as a consequence, more intense construction of residential houses is observed in regions where the economic potential has concentrated.

The climatic conditions in Russia are a factor due to which special requirements are imposed on a method used to generate heat. As is well known [1], combined generation of electricity and heat at thermal power stations (TPSs) offers, along with fuel saving, essential social and environmental advantages of such energy generation method. Despite the fact that many alternative energy- and resource-saving heat supply technologies have emerged (such as heat pumps and thermal energy storages), the use of which makes it possible to exclude the use of expensive heat networks, which are also characterized by labor-consuming repair, combined generation of heat and electricity still remains an important choice when the problem of supplying heat to entire urban areas, especially large cities is to be dealt with. Therefore, the need to construct new and retrofit existing cogeneration steam turbine units (STUs) is beyond question.

Competition among turbine works has become essentially more intense as world-level manufacturers of steam turbine equipment emerged. Extensive use of modern information technologies in all stages of the STU lifecycle is one of possible ways for improving the competitiveness of the manufactured equipment and manufacturing process as a whole.

In automating any lifecycle stage of cogeneration STUs, e.g., the stage of working out their design, a partial information model has to be developed for the subject area under consideration as a totality of concepts (entities), values of their attributes (properties), and correlations. In constructing a model, concepts reflecting the subject area entities are formed first, after which a set of attributes belonging to these concepts is generated, and finally, correlations between the concepts are established that correspond to relations between the subject area entities. The information model of the STU construction design process serves for exchanging information about equipment. That is, on one hand, this model is a source of information for all application systems used at the given stage (including drawing, computation, text, document handling ones, etc.), and on the other hand, it unites all results from the operation of these systems. The main difficulty is that an extremely large set of methods, languages, and models for representing information about a steam turbine unit is used in practical applications.

The progress achieved in development of web technologies opens the possibility to create so-called "virtual enterprises" uniting specialists working at different institutions situated in different territories and spatially separated from each other at distances of several hundred and even thousand kilometers. By using the technology of continuous acquisition and life cycle support (CALS) for a product, it becomes possible to 
create a "virtual enterprise" incorporating specialists in designing and erection, operating personnel of power stations, and repair services. As a result, the period of time taken to design, manufacture, and commissioning the equipment is minimized to the maximum possible extent. Similarly, less time is required for repairing or modernizing this equipment.

The development of technologies for rendering information support to products has brought about a whole class of information systems for product lifecycle management (PLM systems), the use of which makes it possible to render information support to a product not only during the stages of its design and manufacture, but also in other lifecycle stages, both at the manufacturing enterprise itself and beyond its boundaries. With such an arrangement, all parties involved in the product lifecycle not only receive but also share information about all changes occurring with the product in the course of its operation, maintenance, and repairs. The Windchill family of software tools developed by the PTC Company from the United States, which is available with the authors, may serve as an example of such a PLM system.

The information used inside each organization constituting the basis of a virtual enterprise is distributed over a multitude of computers and is stored in a corporate database and also in the form of various files, reports, and e-mail messages. In order to simplify access to all information, a network with internal servers has to be created. The architecture of a computer network in which the Windchill family of software is incorporated is based on the use of web technologies. Being an information infrastructure of the enterprise, the Windchill software system includes tools for organizing the document circulation process and various sorts of databases. The Windchill system contains mechanisms for protection against attempts to get unauthorized access and means for limiting access rights to information for different categories of users. Owing to links with corporate databases, file servers, and document warehouses, the Windchill system provides different kinds of information to enterprise employees via a unified interface.

The most attractive feature of Windchill-based information environment is that neither much effort needs to be applied nor a large sum of money has to be spent for setting it up. Enterprises fitted with computers united into a local area network are in fact already prepared for incorporation of the Windchill system. Thus, web technologies should be used as the basic technology in elaborating a system for providing continuous information support to the turbine unit lifecycle. Nonetheless, both advantages and disadvantages of these technologies should be borne in mind.

The advantages of web technologies are stemming from the features laid down during their development and consist in the following:
- Cohesiveness of heterogeneous data is achieved through the use of hypertext.

- The browser (the web server client program) serves as a unified and fairy simple user interface.

The fact that a corporate network is an excellent platform for publishing information inside the enterprise is another circumstance that should be related to advantages of web technologies. A web browser is accessible for almost any client system, whereas software for group work may be lacking in some other platforms. Web servers do not require so powerful hardware in terms of processor speed and hard disk space as, for example, in classic software packages for group work like LotusNotes. The market of software for web servers is characterized by a high level of competition, due to which the users are not rigidly linked to a single vendor. Nonetheless, all of the involved computer programs show excellent interaction. Web technologies are extendable and can be used in regional computer networks.

The drawbacks of web technologies (which were also laid down during their development) boil down to the fact that the application systems for collective work do not have so powerful capacities as in the traditional software intended for group work. There is a limited set of tools for linking web servers to databases and to other auxiliary application systems. There is a need to organize and support operation of individual application systems, such as e-mail and web servers instead of using a single unified system as in packages intended for group work. Neither the HTML language nor the HTTP protocol has sufficient capacities for development of client-server application systems. Nonetheless, the advantages of web technologies outweigh their shortcomings.

In what follows, we will show, taking one quite realistic project as an example, how the use of modern information technologies can help in solving technical and social problems of an individually taken urban settlement.

We assume that a thermal power station (TPS) with the cogeneration ratio $\alpha_{\operatorname{cog}}=0.5$ is available in a settlement (e.g. in the city of $N$ ). This means that the cogeneration turbines and hot-water boilers installed at the TPS operate with equal heat loads at the minimal outdoor air temperature.

We now assume that a new microdistrict has been built and inhabited as a result of accelerated growth of residential construction and population of the city of $N$. The heat load burden imposed on the TPS has increased due to connection of this residential district. To cover the increased heat load, additional hot-water boilers are installed at the TPS with incorporating them into the common-station scheme in parallel with the existing hot-water boilers. The additional heating system network water passes through the turbine's horizontal delivery-water heaters (HDWHs), after which it enters into the main and additional hot-water 


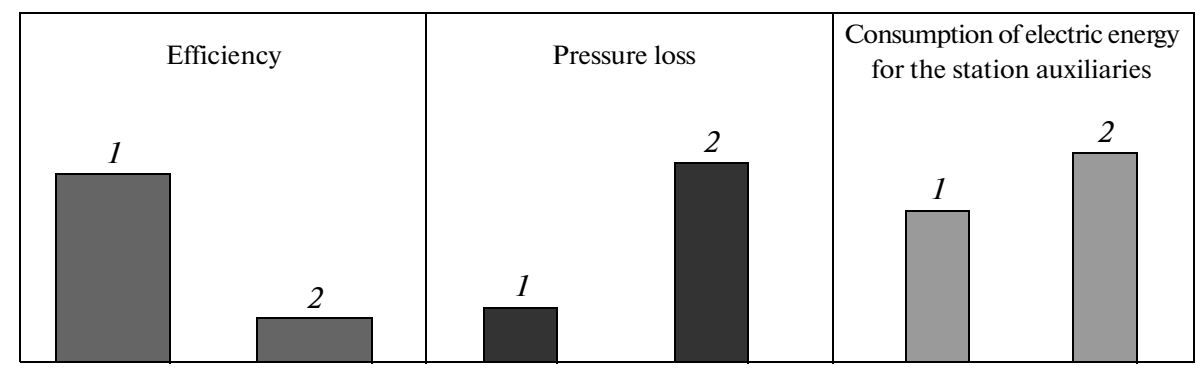

Fig. 1. Changes occurred in the turbine unit main parameters after connecting a new residential district to the TPS. (1) Before the connection and (2) after the connection.

boilers. With the new turbine-to-hot-water-boiler load ratio, $\alpha_{\operatorname{cog}}$ drops to approximately 0.30 , and, accordingly, the flowrate $\mathrm{G}$ of network water through the HDWHs increases by a factor of $1.4-1.6$ as compared with its nominal value.

Specialists of the TPS Equipment Adjustment and Testing Department revealed a few interconnected phenomena (Fig. 1) in the course of carrying out planned periodic tests of equipment and processing the test results using the Ekspluatatsiya (Operation) software system [2]:

-A drop occurred in the intermediate-pressure cylinder (IPC) efficiency.

-An increase of pressure loss occurred in the pipeline supplying steam to the second-stage deliverywater heater (HDWH-2) due to increased steam flowrate to the HDWH-2.

-A growth of power consumption for the plant auxiliaries occurred due to pumping a larger amount of network water.

The TPS Chief Engineer formulates the following problem: a need arose to modernize the turbine with the aim to increase its electric power output while keeping the same flowrate of heat to the turbine unit. An employee in charge for contacts with the Turbine Works opens the Turbine Works corporate portal in the PLM system environment and draws up a report about the problem in the Management of Changes system, attaching documents containing the TPS heat load variation curves and the results of equipment tests (Fig. 2).

Based on the received report about the problem, the PLM system Manager of Changes draws a request for change and forwards it to the Change Assessment Team, which arrives to the following conclusions based on an analysis of the situation:

(1) As the flowrate of network water increases, its temperature at the HDWH inlet remains unchanged and decreases at its outlet. Owing to this circumstance, it is possible to decrease the pressure in the upper controlled steam extraction along the flow of network water, due to which the turbine electric power output increases by $\Delta N_{\mathrm{el}}$ with the flowrate of heat to the turbine unit remaining unchanged [1].
(2) Better efficiency of the cogeneration turbine with staged heating of network water can be achieved during its operation with an increased network water flowrate by changing the place of steam extraction from the turbine flow path by decreasing the number of stages in the intermediate compartment (IC) and increasing the number of stages in the middle compartment (MC) [3].

(3) The flowrate of network water can be increased by organizing its flow in two passes instead of four ones by modifying the HDWH water chambers.

(4) The yokes of the turbine stages must be modified for rearranging them. Since the IC and MC are made with shrunk-on disks, it is possible to shift the stages in the turbine flow path from one compartment to another. Moreover, the yoke-type construction allows the turbine stages to be removed and replaced by more optimal ones [1]. The change of the power output produced by the T-100-130 and T-250/300240 turbines resulted from increasing the relative network water flowrate $\bar{G}$, defined as the ratio of network water flowrate through the HDWH $G$ to the nominal flowrate (equal to $8000 \mathrm{~m}^{3} / \mathrm{h}$ ), and rearranging the MC and IC stages during operation in the average winter mode and at the nominal steam flowrate is shown in Fig. 3. Different effects obtained from the rearrangement are due to the influence of initial steam parameters, different changes of pressure in the controlled heating steam extractions, and different absolute efficiencies of the stages in which the increase of power output occurs [4].

The Change Assessment Team draws up the document "Notification about Change" and approves the change implementation plan.

The change implementation plan directly involves the activities of several design departments. The Steam Turbine Department (STD) must design a new IPC for the steam turbine; the Department of Heat-Transfer Equipment (HTED) must elaborate a project of retrofitting the HDWH water chambers and determine new parameters of its operation; the Department of Steam Turbine Units (STUD) must elaborate a new STU layout project; and the Document Preparation Department must introduce changes into the docu- 


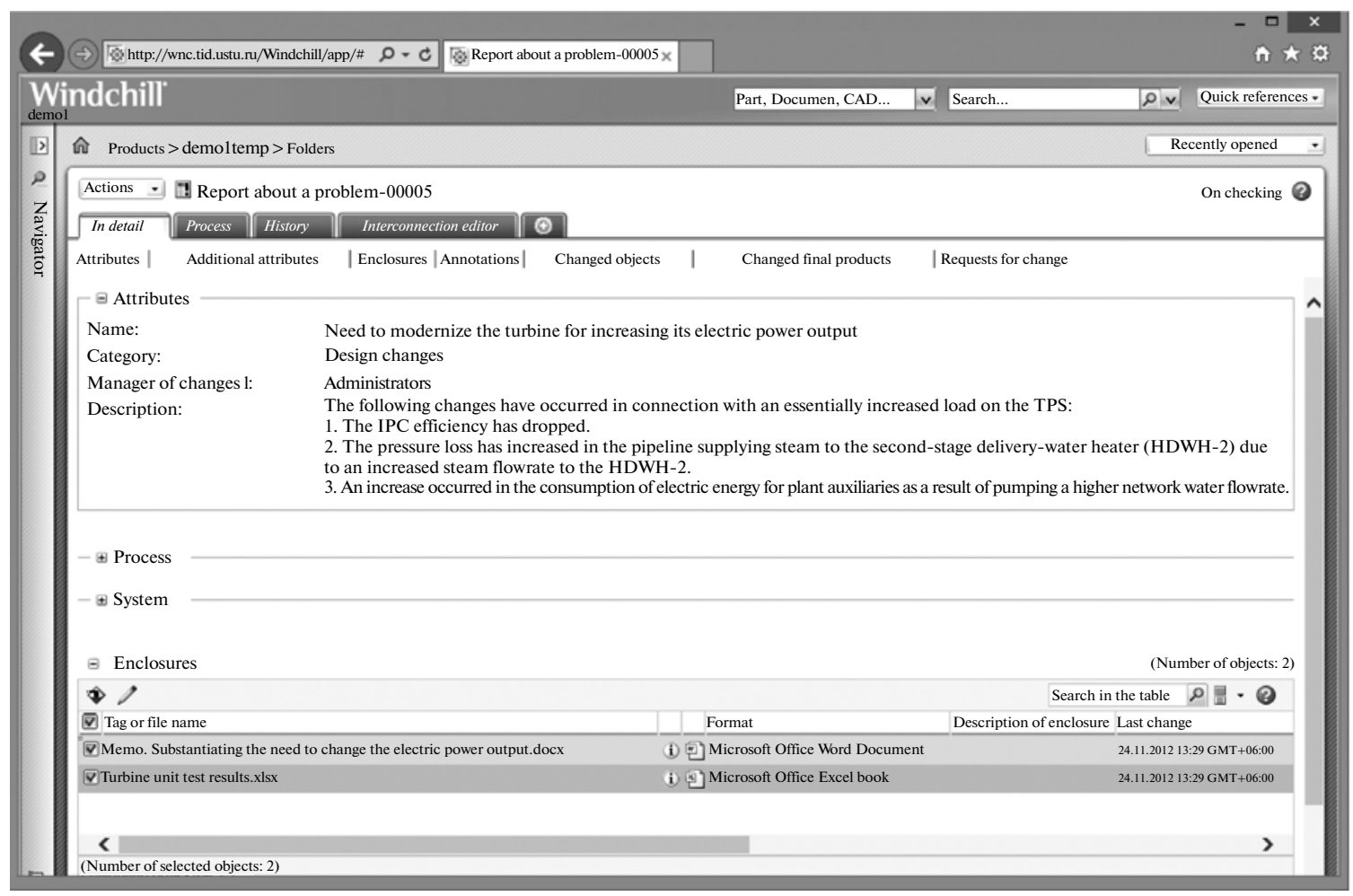

Fig. 2. Report about the problem presented in the PLM system environment.

mentation relating to the components in which changes were made.

The Turbine Works Commercial Service analyzes the change implementation plan and draws up a commercial offer using the enterprise resource planning

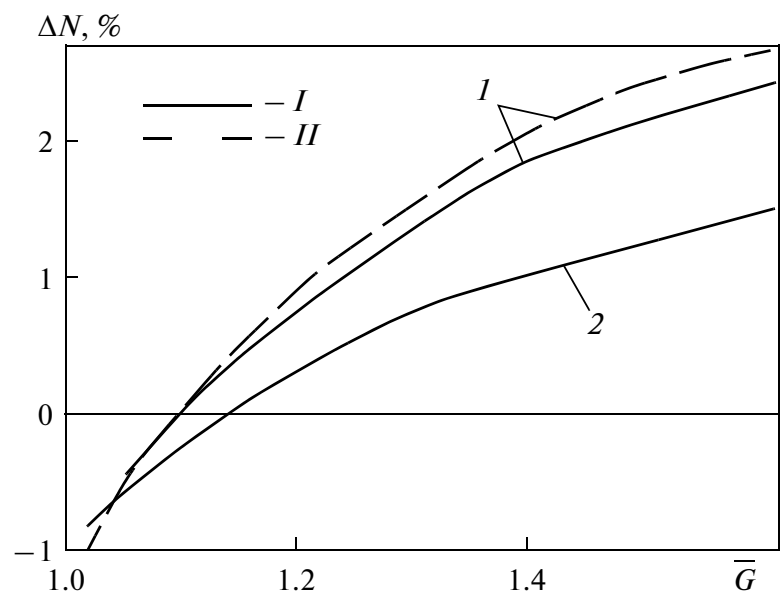

Fig. 3. Change of the turbine power output caused by increasing the network water flowrate $\bar{G}$ during operation in the average winter mode at the nominal steam flowrate as a result of rearranging the pre-extraction stages. (1) T-250/300-23.5 turbine, (2) T-100-12.8 turbine, (I) the shifted stage blade system remains unchanged, (II) the shifted stage is fitted with the optimal blade system. system (the ERP system), places this offer in the PLM system and notifies the TPS top management about the supposed schedules, scope, and cost of retrofitting.

The STD uses the IPC model drawn in a 3D solidstate modeling environment as a prototype. By using the adaptive design technology [5], the designer may concentrate on modeling the IPC rotor with blades, and the cylinder casing is shaped in accordance with the rotor. Application of adaptive design technology is justified in the given case by the fact that the changes are mainly concerned with placing the hoods of district heating extractions. Taking into account the results obtained from the analysis of situation performed by the Change Assessment Team (see point 4), the STD proposes to use an optimized design of shrunk-on disks.

In doing the work on modernizing the HDWH water chambers, the HTED widely uses the templates of parts and family tables, and applies the techniques of parametric and adaptive designing with using the design experience perfected in constructing the heattransfer apparatuses for steam turbine oil supply systems [6]. An automated procedure for designing the tube bundle layout is realized in analyzing the new parameters of HDWH operation, using which this design procedure is accomplished within the minimal period of time.

With such an approach to designing the layouts of tube bundles, all the designer has to do in working out 


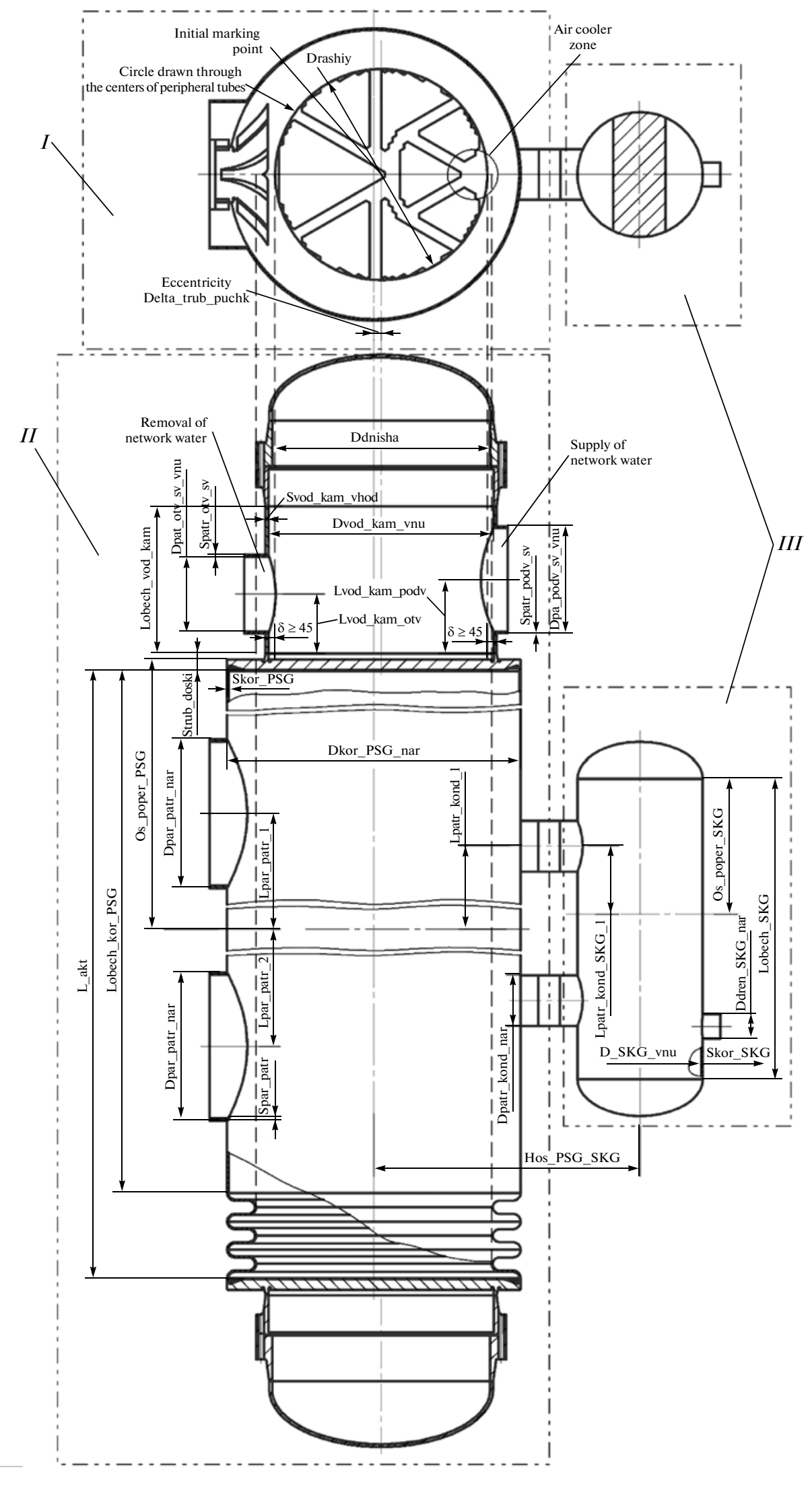

Fig. 4. Basic $2 \mathrm{D}$ sketch of the heater. (I) Tube bundle layout, (II) main structural components of the heater, and (III) hot well. 


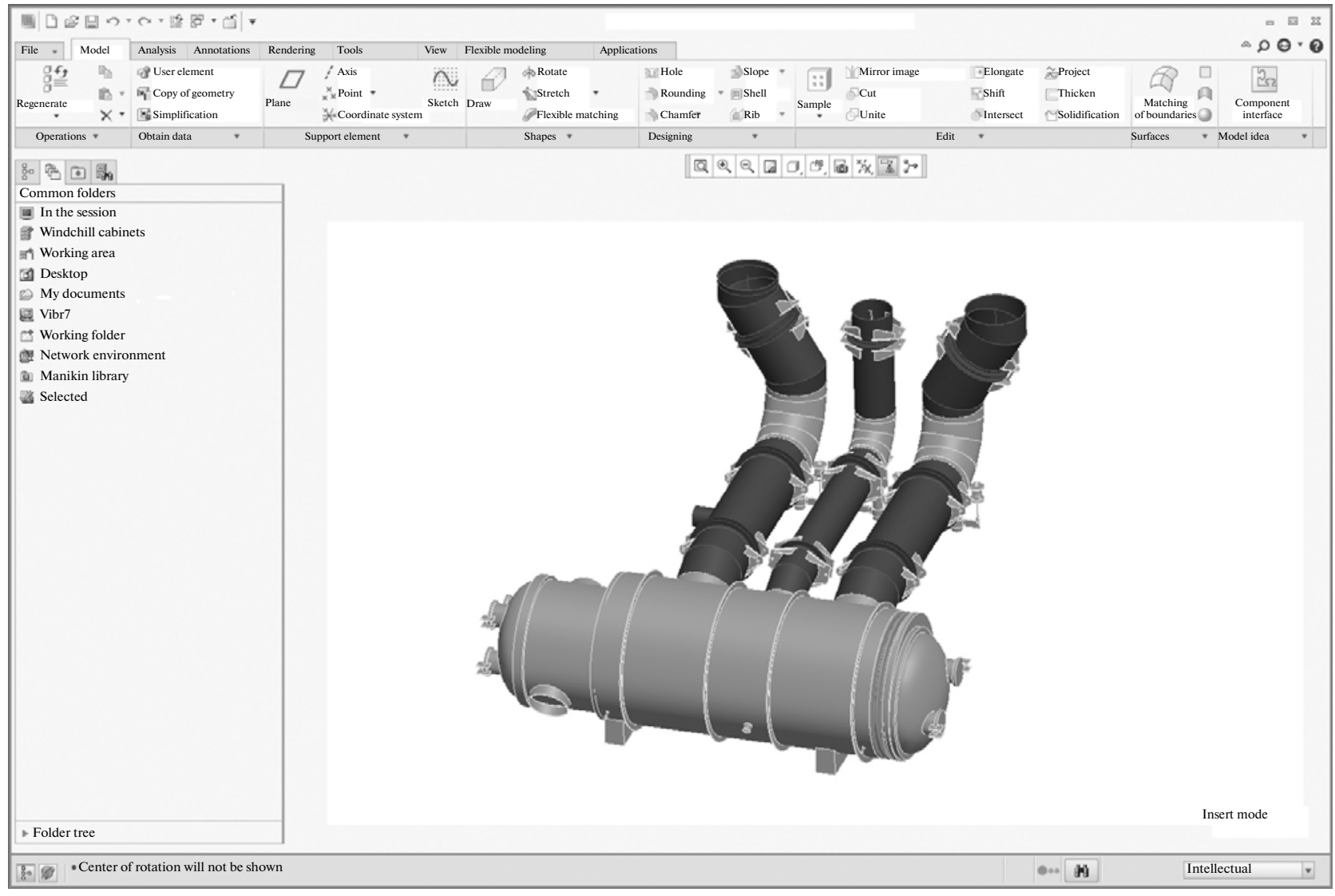

Fig. 5. Fragment of the STU layout.

the layout of holes in tube sheets is to choose a possible version from the table of families and to make minimal correction in this version after regenerating the model of the facility being designed. In designing an HDWH tube bundle, the layout is developed not only for the tube sheets, but also for the intermediate partitions. Thus, the use of one edited template of the layout of holes in these parts adds much flexibility to the work and reduces labor expenditures for carrying out routine operations.

Figure 4 shows the 2D parametric sketch of an HDWH the use of which allows essentially higher productivity of designer labor to be achieved.

Owing to the possibility of using the thermophysical parameters of heat carriers/coolants and strength characteristics of the materials used in a construction, the meaning of the "parameterization" term is broadened beyond the limits of geometrical definitions,

\footnotetext{
${ }^{1}$ Parametric elements and dependences are indicated in Fig. 4 instead of dimensions. The use of these elements makes it possible to manipulate with the geometrical characteristics of the sketch by means of a dedicated template in the form of a table in which the values of parametric elements are entered (parameterization). Logic expressions and dependences, as well as thermophysical properties of medium and material strength characteristics may also be used in the table.
}

which is quite consistent with the modern requirements for computer-aided design tools [7].

In its work on designing an STU layout, the Steam Turbine Department uses a computer-aided design system as the main tool, the basic components of which include a 3D solid-state modeling system and a library of STU equipment models, the content of which increases with each new facility.

The technology of designing layouts with the use of modern information technologies is described in detail in [8]. In this article, we present, as an example, the fragment of STU layout including a delivery-water heater with the steam supply pipelines connected to it (Fig. 5).

The Document Preparation Department is notified, as all the remaining departments, about the progress of implementing the STU retrofitting project by means of the PLM system. The problem of updating assembly and operating manuals, as well as catalogues and guides for maintenance and repair, is solved easier if the documentation is prepared using the tools of technical illustrations (e.g., products of the Arbortext family developed by the PTC Company). If the turbine and turbine equipment are designed in a $3 \mathrm{D}$ modeling environment, the drawings, specifications, 
and guides associatively connected with it are drawn up in an almost automatic manner.

Reclaiming the equipment that has worked out its service life is another important stage of the STU equipment lifecycle. Unlike the nuclear power industry, in which much attention is paid to the reclaiming stage, the practice that has been established in the thermal power industry of Russia is such that equipment often operates up to the natural end of its life. Application of modern information technologies could play its positive role also in this stage. The manufacturer can put a safety margin for ensuring the required failure-free operation of the equipment already at the design stage. In this case, the most optimal alternative is a design in which all the main components of equipment work out their service life simultaneously. In this case, the replacement of equipment that has worked out its service life will facilitate introduction of the equipment and technologies most advanced by that moment of time. However, matters concerned with reclaiming thermal power equipment require more detailed consideration, which is beyond the scope of this article.

Thus, wide use of modern information technologies and means of communication between the participants involved in the STU equipment lifecycle will comprehensively help solve the problems faced by power engineers and machinery construction engineers. If we succeed in setting up the possibility of prompt and full-valued interaction not only between the STU manufacturers and operating personnel, but also in incorporating the departments of transport companies, erection, repair and service organizations into a so-called "virtual enterprise," the problem of improving the competitiveness of the modern Russian economy will surely be solved.

\section{REFERENCES}

1. G. D. Barinberg, Yu. M. Brodov, A. A. Gol'dberg, et al., Steam Turbines of the Ural Turbine Works, Ed. by Yu. M. Brodov and V. V. Kortenko (Aprio, Yekaterinburg, 2010) [in Russian].

2. V. I. Brezgin, K. E. Aronson, I. L. Kozhevnikov, et al., "The Ekspluatatsiya 3.0 Software System," A Certificate of Official Registration of a Computer Program C. 2003612283 RF, No. 2003611755, Applied on August 7, 2003, the Official Bulletin of the Russian Agency for Patents and Trademarks "Progr. EVM, Bazy Dann., Topol. Mikroskhem, No. 1 (46), 12 (2004).

3. G. D. Barinberg, E. I. Benenson, and I. I. Gol'dberg, "A method for operating a cogeneration turbine unit," USSR Inventor's Certificate No. 1495450, Byul. Izobr., No. 27, 103 (1989).

4. E. I. Benenson and G. D. Barinberg, "The efficiency of a cogeneration station equipped with T-250/300-240 turbines operating with a reduced cogeneration ratio," in Proceedings of TsNIITEITyazhmash, Moscow, 1988), pp. 17-21.

5. I. P. Norenkov and P. K. Kuz'mik, Information Support to Science-Intensive Products. CALS Technologies (Bauman MGTU, Moscow, 2002) [in Russian].

6. K. E. Aronson, Yu. M. Brodov, A. Yu. Ryabchikov, et al., "Experience gained from development of modernized oil coolers for the oil supply system used in 800-MW turbines," Therm. Eng, No. 8, 636 (2009).

7. I. P. Norenkov, "Approaches to designing automated systems," Nauka i Obraz., Electron. Nauchno-Tekhn. Izd., No. 6 (2005), http://techmomag.edu.ru/doc/ 52253.html.

8. T. L. Shibaev, A. A. Gol'dberg, and V. I. Brezgin, "Using computer-aided design systems for developing layouts of steam-turbine units," Therm. Eng., No. 8, 692 (2008).

Translated by V. Filatov 